Kırgızistan’da Devlet Borçları ve Borç Yönetimi

\title{
Public Debt and Public Debt Administration in Kyrgyzstan
}

\author{
Tolkun Zhumakunova (Kyrgyzstan-Turkey Manas University, Kyrgyzstan) \\ Asst. Prof. Dr. Raziiakhan Abdieva (Kyrgyzstan-Turkey Manas University, Kyrgyzstan)
}

\begin{abstract}
Public debt and public debt administration in recent years became significant economic problem of most countries. After the collapse of the Soviet Union, Kyrgyzstan has faced with public debt problem. Sharp decline of production, high level of unemployment and the need for economic and structural reforms during transition to market economy caused a large budget deficit.

Budget deficit and public debt problems still remain as one of important macroeconomic issues in Kyrgyzstan. The purpose of our paper is to overview public debt politics and analyze public debt administration in Kyrgyzstan. Also to investigate legal framework of public debt, transparency, risks and effectiveness of public debt administration in Kyrgyzstan.
\end{abstract}

\section{Giriş}

Kamu borçları günümüzde çoğu ülkelerin güncel sorunlarındandır. Özellikle az gelişmiş ülkelerde ekonomik büyümeyi hızlandırmak amacıyla kamu borçları sürekli artmaktadır. Bu tür ülkelerde ülke içindeki sermaye yetersizliğinden dolayı daha çok dış borçlanmaya dayanılmaktadır.

Kırgızistan bağımsızlığını kazandığ 1991 yılından sonra çok ciddi şoklarla karşı karşıya kalmıştır. Üretimin yarı yarıya düşmesi, Sovyetler Birliğinin genel bütçesinden gelen transferlerin durdurulması ve eski SSCB ülkeleri ile ticari bağların kopması kamu gelirlerinin azalmasına neden olmuştur. Diğer yandan ise ülkede yapısal ve ekonomik reformlar ve sosyal harcamalar kamu harcamalarını arttırarak bütçe açığının oluşmasına ve devlet borçlarının yükselmesini ortaya çıkarmıştır.

Borçlar gelecekteki mükellefler üzerindeki yük olduğundan dolayı borçların sürdürülebilir düzeyde olması önemlidir. Bunun için borçların yapısı ve özellikleri (imtiyazlı veya imtiyazlı olmaması, kısa ve uzun vadeli olması v.s.) etkin kullanıma ve zamanında borçları geri ödemeye dikkat edilmelidir. Diğer bir değişle borçların yönetimi ülkenin geleceği ve borçların ekonomi üzerindeki etkisi açısından da önemli hale gelmektedir.

Çalışmamızın amacı Kırgızistan'da kamu borçlarının ve borç yönetiminin analizini yapmaktır. Ülkede borçların yapısı, kullanım alanları, borçlarla ilgili bilgilerin saydamlığı ve borç yükünün durumu incelenecektir. Sonuç olarak da borç yönetim ile ilgili bazı önerilerde bulunulacaktır. Girişi izleyen 2. Bölümde genel olarak borç kavramı ve borç yönetiminin teorik analizi, 3. Bölümde Kırgızistan'daki genel ekonomik durum, 4. Bölümde Kırgızistan'da devlet borçlarının analizi, 5. Bölümde dış borçlar incelenerek 6. Bölümde de sonuç ve öneriler sunulmuştur.

\section{Genel Olarak Borç Kavramı ve Borç Yönetimi}

Borç ödünç alınmış herhangi bir şey karşılığında yerine getirilmesi gereken yükümlülüğü anlatan bir ilişkidir, borçlanma ise, belli bir süre sonra ödenmek üzere para veya benzeri şeylerin ödünç alınmasıdır (Eker ve Meriç, 2000; Adıyaman, 2006). Kamu borçları ise ekonomik açıdan istikrasızlıklarla mücadele edilmesi, büyüme ve kalkınmanın finansmanın sağlanması gibi nedenlerle başvurulan finansman kaynağıdır (Çaşkurlu, 2003). Diğer bir tanıma göre de devlet borçlanması, devletin bir özel hukuk tüzel kişisi olarak isteğe bağlı ve bedel karşılığında, alacaklıya ödenme vaadi ile iç ve dış kaynaklardan elde ettiği gelirdir (Orhaner, 1997).

Borçlar sağladıkları kaynak bakımından iç borçlar ve dış borçlar olmak üzere ikiye ayrılmaktadır. Devlet ülke içindeki tüzel ve özel kişilerden veya ülke dışındaki tüzel ve özel kişilerden borçlanabilmektedir. İç borçlar ülke içindeki tasarrufları ve sermayeyi azaltırken dış borçlar milli geliri arttırıcı ve ekonomik büyümeyi hızlandırıcı etkide bulunabilir. Fakat diş borçların çok yüksek seviyelere gelmesi borç servisine olan harcamaların yükselmesini ve sermayenin ülkeden çıkışına neden olabilmektedir. Dolayısıyla borçların ekonomi üzerinde olumsuz etkilerinin önlemek ve ekonomik gelişmeyi engellememesi için etkin bir borç yönetimine gerek duyulmaktadir.

Borç yönetimi düşük maliyet ve asgari risk ile piyasalardan fon sağlanmasıdır (Ateş, 2002). Borç yönetimi devletin finansman ihtiyacını riskleri ve maliyeti en düşük seviyede tutarak karşılama sürecidir. Borç yönetimi sürecini üç aşamaya ayırabiliriz. Bunlar: karar alma, kullanma ve geri ödeme aşamalarıdır. İlk aşamada borçlanmanın türü, vadesi ve riskleri ele alınarak herhangi bir borçlanmaya karar verilecektir. İkinci aşamada elde edilen borçların kullanım alanları belirlenecektir. Burada şeffaflık ve etkinlik ilkelerine uygun olarak kullanmak önemlidir. Diğer bir değişle alınan borçların ekonomik gelişmeyi hızlandırarak geri ödenmesini kolaylaştıracak ve gelir getiren alanlara harcanması ve borçların nasıl kullanıldığı ile ilgili raporların sunulması gerekmektedir. Borç 
yönetimi alınan borçların zamanında geri ödenmesi ile sonuçlanmaktadır. Böylece, borç yönetimi riskleri göz önüne alarak düşük maliyetle sağlamak ve borçları etkin kullanarak geri ödenmesi ile sonuçlayan bir süreçtir. Borç yönetiminde devlet borçlarının ekonomi üzerindeki negatif etkileri de önlenilmeye çalışılmalıdır.

Borç yönetimi ekonominin genel özellikleri ve yapısına uygun biçimde, alınacak borcun miktarının, ödeme şartlarının, ekonomiye getireceği yükün, borç servis yükünün ağırlaşması durumunda alınabilecek önlemlerin hesaplanmasinı kapsar.

Genel olarak devlet belli bir iktisadi hedeflere ulaşmak için piyasadan sağlanan fonların diğer bir deyişle borçların miktarında ve bünyesinde değişiklikler yapmasıdır diyebiliriz. Borç miktarındaki değişmeler ise belirlenen hedefler gözetilmeden gerçekleşmişse bazı aksi tesirleri olabilecektir. Bu yüzden borç yönetimi ekonomi için önemli rol oynamaktadır.

Canbay (2005) Kırgızistan'da dış borç ve borç yönetimi sorununu incelemiştir. Araştırma sonucunda Kırgızistan'da borç yönetiminin gelişmesi için borçlanma amacının, şartlarının ve borçlanma yoluyla sağlanan kaynakların nasıl kullanıldığının kamuoyu tarafından açıkça bilinebilmesi veya şeffaflığın arttırılması gerektiğini bildirmiştir.

Egeli de (2008) Kırgızistan’da dış borçların sürdürülebilirliğini 1993-2006 yıllarına ait verileri kullanarak incelemiştir. Birim kök ve eşbütünleşme testlerinin sonucu Kırgızistan'da dış borçların sürdürülebilirliği uluslararası finansal piyasalara bağlı olduğunu, uluslararası faiz oranlarındaki bir düşme dış borcun değerini arttırdığını, ilgili faiz oranlarının yükselmesi ise Kırgızistan’da likidite kısıtını yaratacağını göstermişstir. Dolayısıyla Kırgızistan'da etkin dış borç yönetimi gerekli olduğu sonucunu bulmuşlardır.

\section{Kırgizistan'da Temel Ekonomik Göstergeler}

SSCB'nın dağılmasından sonra Kırgızistan ekonomisi 1991-1995 yıllarında ciddi krizle karşı karşıya kalmıştır. Eski SSCB ülkeleri ile ticari bağların kopması, genel bütçeden gelen transferlerin durdurulması ve planlı ekonomiden piyasa ekonomisine geçiş dönemindeki karşılaşan sorunlardan dolayı üretimde \% 50 oranında düşüş yaşanmıştır. Enflasyon, işsizlik ve yoksulluk düzeyi keskin bir şekilde artmıştır. 1991-1995 dönemi krizle mücadele ve reform uygulamaları dönemi olmuştur.

Kırgızistan ekonomisi 1996 yılından itibaren tarım üretimindeki artış ve Kumtör Altın madeninin hizmete sokulması nedeni ile büyümeye başlamıştır (DEİK, 2012). Fakat 1998 yılında Rusya'daki mali krizin etkisi ile 1998-1999 yıllarında Gayri Safi Yurtiçi Hasılada (GSYH) düşüş yaşanmıştır. 2000-2001 yıllarında Kumtör maden işletmesinin ve tarımın gelişmesi nedeni ile ekonomi \% 5 oranında büyümüştür. 2002'de ise Kumtör firmasında ortaya çıkan kaza nedeniyle büyüme - \% 0.01'e azalmıştır. 2005 yılında ülkede yaşanan siyasi darbenin negatif etkilerinden dolayı GSYİH -0.1'e küçülmüştür. 2007 ve 2008 yıllarında ise ihracat, özellikle Çin'den Rusya'ya yeniden ihracatın artmasından ve göçmenlerinin transferlerinin artmasından dolayı büyüme \% 8 oranında gerçekleştirmiştir. 2010 yılında tekrar siyasi darbe ve etnik çatışmaların sonucunda üretimde $\%-0.5$ oranında düşüş olmuştur. 2012'de Kumtör altın madencilik firmasının üretimindeki düşüş nedeni ile GSYİH \% -0.08 oranında düşüş yaşamış iken 2013'te bu firmanın üretiminin artması ile ekonomide \% 11 oranında büyüme gerçekleşmiştir.

Dünya piyasalarında petrol fiyatlarında yaşanan azalışlar, petrol ithalatçısı bir ülke olan Kırgızistan'da tüketimi arttırmış, büyümeye de katkıda bulunmuştur. Özellikle altın ihracatındaki ciddi artışlara bağlı olarak ekonomik büyüme hız kazanmıştır. Kırgız mallarına olan talebin azalmasına yol açan ve dolayısıyla 2015 yılında ülkenin altın ihracatı dışındaki ihracatında bir azalış yaşanmasına neden olan Rusya'daki ekonomik durgunluğa rağmen, Kırgızistan ekonomisinde 2014 yılında \%3.6 olan ekonomik büyüme oranı, büyük ölçüde altın üretimindeki yüksek performansa bağlı olarak, 2015 yılında \%7.3'e yükselmiştir.

1993 yılında Kırgızistan'da fiyatların serbest bırakılmasıyla enflasyon oranı yüzde 1363'e yükselmiştir. Sıkı para politikaları uygulamalarının sonucunda 1998 yılında yüzde 10’a kadar düşürülmüştür. Ancak, Rusya krizi nedeni ile 1999 yılında enflasyon yüzde 37'ye ulaşmıştır. S1kı para politikası altında enflasyon 2002-2006 yıllarında \% 2 ile 5 arasında sergilemiştir. Fakat 2007-2008 yıllarında global finansal krizin etkisi ile \% 10,1 ve \% 24,5 'e yükselmiştir. Son yıllarda enflasyon oranı \% 6 ve $\% 7$ civarında tutulmaktadır.

Geçiş döneminin başında üretimin yarı yarıya düşmesi işsizliği hızla arttırmıştır. 1992 yılında işsizlerin resmi sayısı 1,792 iken 1995 'te 50,409'a yükselmiştir. İşsizlik oranı resmi istatistiklere göre 1992 ve 2015 döneminde \% 8 ile 9 civarlarında sergilemiştir. Fakat Economic Intelligence Unit'in verilerine göre 2010 yılında toplam 78.150 işsiz kaydedilmiştir. Kırgızistan'da 2010 yılı işsizlik oranı \%20 olmuştur. Çalışabilir nüfus 2.344 milyon iken, kayıtlı nüfustaki işsizlerin \%14'ü erkekler iken \%16'sını ise kadınlar oluşturmaktadır (DEİK, 2012: 10). Böylece, işsizlik hala ülkenin önemli sorunlarındandır. 


\begin{tabular}{|r|r|r|r|r|r|r|}
\hline Yıllar & $\begin{array}{c}\text { GSYIH'nın } \\
\text { büyüme oranı } \\
\mathbf{( \% )}\end{array}$ & $\begin{array}{c}\text { Enflasyon } \\
\text { oranı (\%) }\end{array}$ & $\begin{array}{c}\text { İşsizlik } \\
\text { oranı (\%) }\end{array}$ & $\begin{array}{c}\text { Ihracat } \\
\text { (milyon \$ ) }\end{array}$ & $\begin{array}{c}\text { Ithalat } \\
\text { (milyon \$ ) }\end{array}$ & $\begin{array}{c}\text { Toplam Diş } \\
\text { Borç } \\
\text { (milyon \$) }\end{array}$ \\
\hline $\mathbf{1 9 9 2}$ & $-13,8$ & 1259 & 8,6 & 317.0 & 420.7 & 5,52 \\
\hline $\mathbf{1 9 9 3}$ & $-15,4$ & 1363 & 8,7 & 360.2 & 447.8 & 231,83 \\
\hline $\mathbf{1 9 9 4}$ & -20 & 95,7 & 8,4 & 340.1 & 317.0 & 368.91 \\
\hline $\mathbf{1 9 9 5}$ & $-5,4$ & 31,9 & 8,7 & 408.9 & 531.0 & 485.14 \\
\hline $\mathbf{1 9 9 6}$ & 7 & 31,9 & 8,7 & 505.4 & 782.9 & 997.36 \\
\hline $\mathbf{1 9 9 7}$ & 9,9 & 23,4 & 8,3 & 603.8 & 646.1 & 1176.06 \\
\hline $\mathbf{1 9 9 8}$ & 2,1 & 10,4 & 9,7 & 513.8 & 755.9 & 1329.86 \\
\hline $\mathbf{1 9 9 9}$ & 3,6 & 37 & 8,2 & 462.6 & 551.1 & 1545.55 \\
\hline $\mathbf{2 0 0 0}$ & 5,4 & 18,7 & 7,5 & 510.9 & 506.9 & 1639.38 \\
\hline $\mathbf{2 0 0 1}$ & 5,3 & 6,9 & 7,8 & 480.3 & 440.4 & 1538.03 \\
\hline $\mathbf{2 0 0 2}$ & $-0,01$ & 2,1 & 12,5 & 498.1 & 552.1 & 1657.06 \\
\hline $\mathbf{2 0 0 3}$ & 7 & 2,9 & 9,9 & 590.3 & 673.0 & 1820.54 \\
\hline $\mathbf{2 0 0 4}$ & 7 & 4,1 & 8,5 & 718,8 & 941,0 & 2224.22 \\
\hline $\mathbf{2 0 0 5}$ & $-0,1$ & 4,3 & 8,1 & 672,0 & 1101,3 & 1957.58 \\
\hline $\mathbf{2 0 0 6}$ & 3,1 & 5,6 & 8,3 & 794,1 & 1718,2 & 2307.71 \\
\hline $\mathbf{2 0 0 7}$ & 8,5 & 10,1 & 8,2 & 1134,2 & 2417,0 & 2597.22 \\
\hline $\mathbf{2 0 0 8}$ & 8,4 & 24,5 & 8,2 & 1617,6 & 4072,4 & 3333.19 \\
\hline $\mathbf{2 0 0 9}$ & 2,9 & 6,8 & 8,4 & 1443,5 & 3040,2 & 3818.96 \\
\hline $\mathbf{2 0 1 0}$ & $-0,5$ & 7,9 & 8,6 & 1468,4 & 3385,8 & 3807.33 \\
\hline $\mathbf{2 0 1 1}$ & 6 & 16,4 & 8,5 & 2380,7 & 4261,2 & 5174.02 \\
\hline $\mathbf{2 0 1 2}$ & $-0,08$ & 2,7 & 8,4 & 2588,3 & 5576,3 & 5705.08 \\
\hline $\mathbf{2 0 1 3}$ & 11 & 6,6 & 8,3 & 2833,2 & 6069,8 & 6470.51 \\
\hline $\mathbf{2 0 1 4}$ & 4 & 7,5 & 8,1 & 2482,7 & 5732,5 & 6949.14 \\
\hline $\mathbf{2 0 1 5}$ & 3,4 & 6,5 & 8 & 1606,2 & 4069,5 & 7198.85 \\
\hline
\end{tabular}

Tablo-1: Kırgızistan'ın Temel Ekonomik Göstergeleri Kaynak: Dünya Bankası 2017, KC Merkez Bankası Bülteni, Bişkek, 6/2005 ve KC Merkez Bankası Bülteni, Bişkek, 12(251)/2016 verilerine göre hazırlanmıştır

Dünya piyasalarında petrol fiyatlarında yaşanan azalışlar, petrol ithalatçısı bir ülke olan Kırgızistan'da tüketimi arttırmış, büyümeye de katkıda bulunmuştur. Özellikle altın ihracatındaki ciddi artışlara bağlı olarak ekonomik büyüme hız kazanmıştır. Kırgız mallarına olan talebin azalmasına yol açan ve dolayısıyla 2015 yılında ülkenin altın ihracatı dışındaki ihracatında bir azalış yaşanmasına neden olan Rusya'daki ekonomik durgunluk dolayısı ile Kırgızistan ekonomisinde 2014 yılında \%3.6 ve 2015 yılında \%3.4 oranında büyüme gerçekleşmiştir.

İhracat bağımsızlığı kazandıktan sonra 5 kat artmışsa ithalat 9,6 kat artmıştır. Dolayısı ile dış ticaret açığı günümüzde yüksek olmaktadır. İhracatın GSYİH'ya oranı \% 55 civarında iken ithalatın GSYİH'ya oranı \% 80'den fazladır. İhracatın düşük olması ülkenin borçların geri ödemesini daha da zorlaştırabilmektedir.

Yukarıdaki Kırgızistan'ın genel ekonomik durumu dikkate alınarak ülkemizin borçlanma nedenlerini aşağıdaki gibi sıralayabiliriz:

- Sovyetler dönemindeki genel bütçeden ayrılan kaynak transferlerinin durdurulmasi;

- Sovyetler dönemi dağılması nedeniyle yapısal reformların finansmanı;

- Sovyetlerin dağılmasıyla ülkeler arası ödeme sisteminin yıkılması, bu sisteminin yıkılmasından dolayı ülkeler arası şirketlerin birbirlerine olan ödemelerindeki gecikmeler;

- Devletin iç borçlanma kaynağının kısıtlılı̆̆ı;

- Bütçe açıklarının finansmanı;

- Döviz ihtiyac1;

- $\quad$ Sosyal ve altyapı hizmetlerinin üretimi.

\section{Kırgızistan'da Devlet Borçları}

Kırgızistan'ın bağımsızlığını kazandığı ilk yıllarda kaynak sıkıntısı ile karşılaşmıştır. Bu durum bütçe açığının büyümesine neden olmuştur. Bütçe açığı 1993-1994 yıllarında GSYİH'ya oranla \% 7 iken, 1995 yılında \% 12'ye çıkmıştır. Fakat 2001 yılında bütçe açı̆̆ı \% 0.4'e kadar azalmıştır (Koyçuyev, 2003: 454). 2008'de ekonomideki canlanma ve göçmen transferlerinin yardımı ile bütçe fazla vermiştir. 


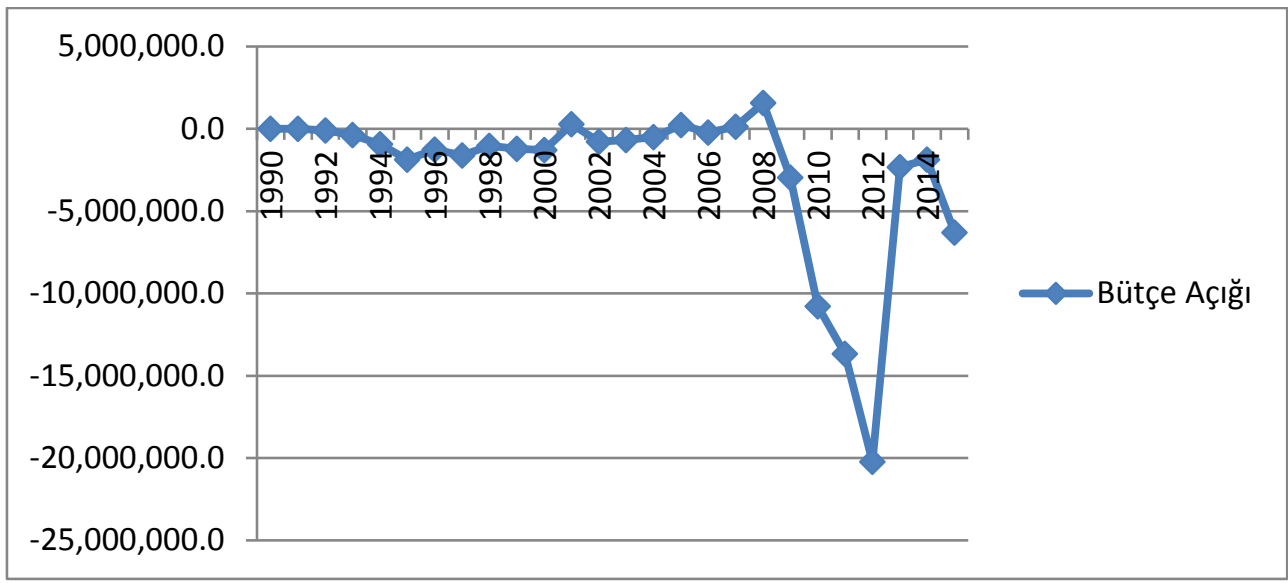

Şekil-1: Kırgızistan'da Bütçe Açı̆̆ı (bin som) Kaynak: Kırgız Cumhuriyeti İstatistik Komitesi (05.10.2016)

2009'dan itibaren bütçe açığı hızla artmaya başlamıştır ve 2012'de bütçe açığı GSYİH'ya oranla \% 6.6'ya çıkmıştır. 2015'te ise bütçe açığı GSYH'ya oranla 1.5'i oluşturmuştur. Bütçe açığı Kırgızistan'da daha çok diş borçlanma ile kapatılmaktadır. Kırgızistan'ın toplam dış borç stoğu 31 Aralık 2016 tarihi itibariyle 4105,44 milyon dolardır. Bunun \% 92.1'i dış borçlar ve \% 7.9'u iç borçlardan oluşmuştur.

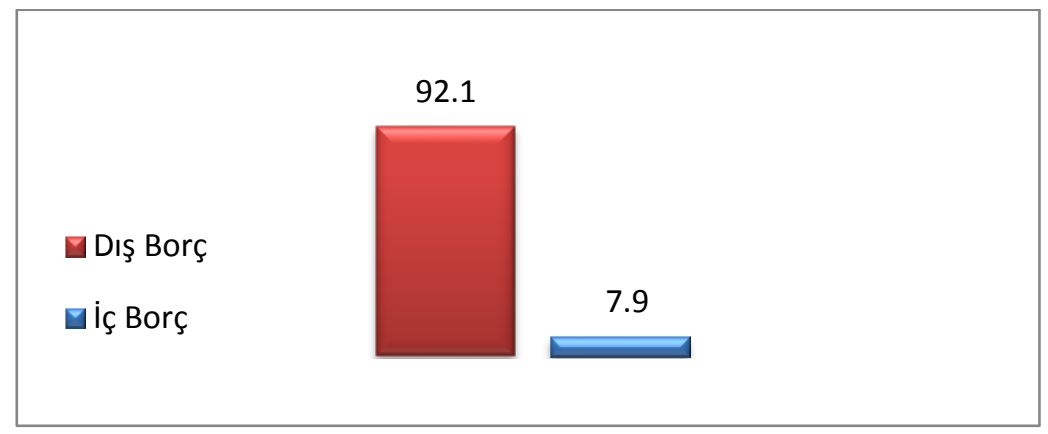

Şekil-2: Kırgızistan'da Devlet Borçlarının Dă̆ılımı Kaynak: Kırgızistan Cumhuriyeti Maliye Bakanlığı (20/02/2017)

1993 yılında dış borçların GSYİH'ya oranı \% 7.2 iken 1999 yılında \% 105'e çıkmıştır. Sonraki yıllarda azalarak 2005 yılında \%76.5 ve 2014'te 46.4'ü oluşturmuştur. Kırgızistan, yüksek dış borcu sebebiyle Dünya Bankası ve IMF tarafından ortak yürütülen Aşırı Borçlu Fakir Ülkeler ("HIPC”) Programına 2006 yılında başvurarak 1 milyar dolara yakın borcun silinmesi gibi imkanlardan faydalanmayı gözden geçirmiştir. Ancak, bu programa dahil olunmasının prestij kaybına sebep olacağı nedeniyle, ayrıca IMF ve Dünya Bankası'nın ülke ekonomisi üzerinde bulunacağı çeşitli taleplerin yükümlülügüne girilmek istenmemesinden 2007 yılı Şubat ayında hükümet bu programa dahil olmaktan vazgeçmiştir (DEİK, 2012: 7).

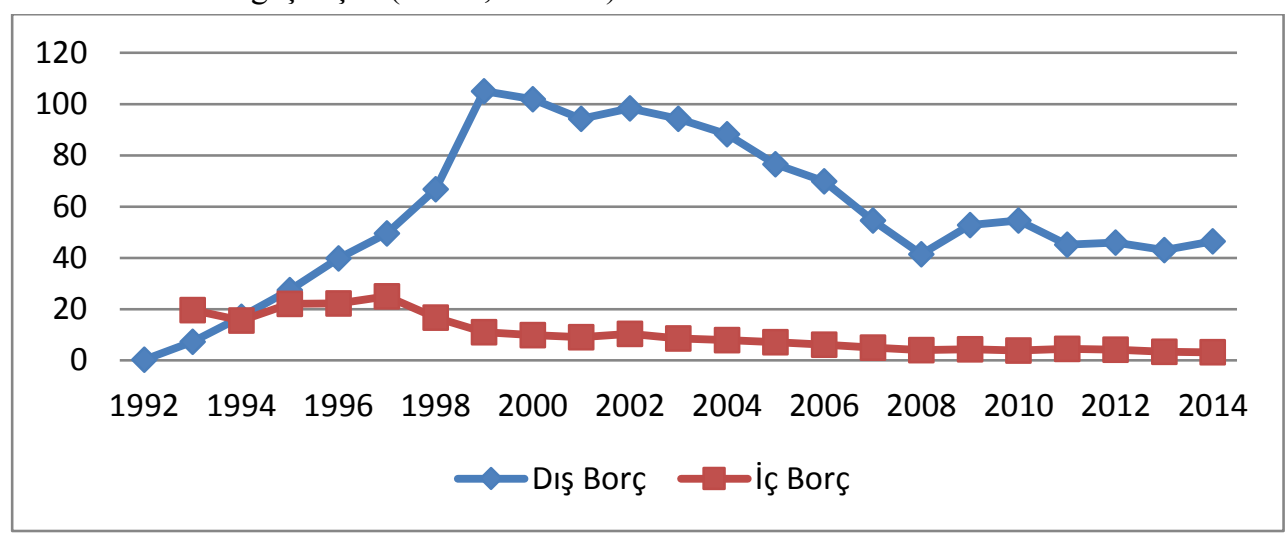

Şekil-3: Kırgızistan'da İç Borç ve Dış Borçların Gelişimi, (GSYİH'ya oranla) Kaynak: Kırgızistan Cumhuriyeti Istatistik Komitesi (10/04/2017)

İç borçlar 1998 yılına kadar Merkez Bankadan kredi alarak borçlanırken 1998 yılından sonra bu borç türü durdurulmuştur. Günümüzde iç borç hazine bonoları ve devlet tahvilleri aracılığı ile alınmaktadır. 
2014 yılında dış borçlar GSYİH'nın \% 49.5'sini iç borçlar 3.1'ini oluşturmuştur. Ancak 2015 y1lında devlet borçlarının GSYİH'ya oranı \% 64,6'ya yükselmiştir. Bunun nedeni nominal GSYİH'nın seviyesinin beklenildiğinden düşük olduğu ve ulusal paranın değer kaybetmesidir (IMF, 2016: 8).

Kırgız Cumhuriyeti Hükümetinin 6 Ekim 2016 tarihindeki 532 No'lu Kararname ile 2016-2018 y1llarında Kırgız Cumhuriyet'inde Devlet Borçları Yönetimi Stratejisi kabul edilmiştir. Bu stratejide devlet borçlarının yönetiminin temel amaçları Hükümetin finansal ihtiyacını en düşük maliyet ve asgari risk ile karşılama, ülkenin menkul kıymetler piyasasını geliştirmek ve devlet borçlarının sürdürülebilirliğini desteklemektir.

Stratejide dış borçlar ekonomik büyüme ve fakirliği azaltacak olan proje ve programlara öncelik verileceği belirtilmiştir. Bir taraftan alınan dış borç dış borçların \% 50'sinden aşmamalıdır.

İç borçlarla ilgili Kırgız Cumhuriyeti Hükümeti devlet iç borç senetlerinin süresini arttırmaya çalışmaktadır. Bunun için hazine bonolarının payını arttırma ve 2 seneden daha fazla vadeli hazine bonolarının çıkartmaya yönelik faaliyetler yapılacaktır. Devletin iç borçlanmasının temel amaçlarından biri menkul kıymetler borsasının gelişmesine katkıda bulunmaktır.

\begin{tabular}{|l|c|c|c|c|c|}
\hline & $\mathbf{2 0 1 2}$ & $\mathbf{2 0 1 3}$ & $\mathbf{2 0 1 4}$ & $\mathbf{2 0 1 5}$ & $\mathbf{2 0 1 6}$ \\
\hline Hazine Bonoları & & & & & \\
\hline Hacmi (milyon som) & 109,1 & 48,1 & 83,1 & 249,7 & 130,8 \\
\hline İslemler sayısı & 11 & 4 & 2 & 10 & 5 \\
\hline $\begin{array}{l}\text { Ortalama ağırlıklı faiz oranı } \\
\text { (bir dönem içinde, \%) }\end{array}$ & 8,53 & 8,48 & 8,45 & 13,38 & 8,14 \\
\hline Ortalama süre (günler) & 174 & 247 & 298 & 185 & 171 \\
\hline Devlet Tahvilleri & & & & & 77,0 \\
\hline Hacmi (milyon som) & - & 98,8 & - & 411,9 & 2 \\
\hline İşlemler sayısı & - & 1 & - & 7 & 15,88 \\
\hline $\begin{array}{l}\text { Ortalama ağırlıklı faiz oranı } \\
\text { (bir dönem içinde, \%) }\end{array}$ & - & 14,59 & - & 14,93 & 342 \\
\hline Ortalama süre (günler) & - & 643 & - & 1018 & 2 \\
\hline
\end{tabular}

Tablo-2: Kırgızistan'da İç Borçların Dağılımı Kaynak: Kırgız Cumhuriyeti Merkez Bankası, (02.03.17).

Kırgızistan'da iç borçlar hazine bonoları ve devlet tahvillerinden oluşmaktadır. Hazine bonolarının hacmi giderek arttığı görülmektedir. Özellikle 2015 yılında önceki y1la göre 3 kat artmıştır. Bunun en önemli nedenlerinden biri de bu sene hazine bonolorunun faiz oranın yüksek olduğu sayılabilir. Ortalama sürelerine bakıldığında daha çok 6 aya kadar kısa süreliler tercih edildiği görülmektedir.

Devlet tahvillerinde de 2015 yılında daha çok satışların gerçekleştirildiği ve ortalama faiz oranları \% 14-15 arasında olmuştur. 2016 yılında daha çok 1 yıl satın alınan devlet tahvillerinin süresinin azaldığı farkedilmiştir.

\section{Kırgızistan’ın Dış Borçların Yapısı}

Geçiş ekonomili olan Kırgızistan gibi ülkelerde ülke içindeki kaynak yetersizliğinden dolayı ekonomik gelişme amacıyla dış borçlanma daha uygun olmaktadır. Özellikle orta ve uzun vadeli ve imtiyazlı veya düşük faizli dış borçların toplum içinde ağırlık taşıması önemlidir. Borç servis kapasitesini gösteren Kısa Vadeli Dış Borçlar/TDB Oranının \%15-20 arasında seyretmesi makul karşılanırken \%20'yi aşmaması tercih edilmektedir (Tandırcıŏlu, 2000). Kırgızistan'da kısa vadeli dış borçların payı \% 3-4 arasında ve \% 91.3'ü ise uzun vadeli olduğu görülmüşsür. 


\begin{tabular}{|r|r|r|r|r|r|r|}
\hline Yıllar & $\begin{array}{c}\text { Toplam } \\
\text { Diş Borç } \\
\text { (milyon \$) }\end{array}$ & \multicolumn{1}{c|}{$\begin{array}{c}\text { Artış Trendi } \\
\text { \% }\end{array}$} & $\begin{array}{c}\text { Uzun Vadeli } \\
\text { Borçlar }\end{array}$ & $\begin{array}{c}\text { Kisa Vadeli } \\
\text { Borçlar }\end{array}$ & $\begin{array}{c}\text { Uzun Vadeli } \\
\text { Borç/TDB }\end{array}$ & $\begin{array}{c}\text { Kisa Vadeli } \\
\text { Borç/TDB }\end{array}$ \\
\hline $\mathbf{1 9 9 4}$ & 368.91 & - & 356.0 & 12.83 & 79.7 & 2.9 \\
\hline $\mathbf{1 9 9 5}$ & 485.14 & 31,5 & 472.18 & 12.97 & 77.5 & 2.1 \\
\hline $\mathbf{1 9 9 6}$ & 997.36 & 105,6 & 988.70 & 8.66 & 87.0 & 0.8 \\
\hline $\mathbf{1 9 9 7}$ & 1176.06 & 17,9 & 1143.04 & 33.02 & 85.2 & 2.5 \\
\hline $\mathbf{1 9 9 8}$ & 1329.86 & 13,0 & 1301.67 & 28.19 & 86.5 & 1.9 \\
\hline $\mathbf{1 9 9 9}$ & 1545.55 & 16,2 & 1484.88 & 60.68 & 80.1 & 3.3 \\
\hline $\mathbf{2 0 0 0}$ & 1639.38 & 6,0 & 1510.37 & 129.02 & 78.0 & 6.7 \\
\hline $\mathbf{2 0 0 1}$ & 1538.03 & $-6,2$ & 1490.29 & 47.74 & 81.7 & 2.6 \\
\hline $\mathbf{2 0 0 2}$ & 1657.06 & 7,7 & 1646.81 & 10.25 & 84.1 & 0.52 \\
\hline $\mathbf{2 0 0 3}$ & 1820.54 & 9,9 & 1783.06 & 37.49 & 83.0 & 1.7 \\
\hline $\mathbf{2 0 0 4}$ & 2224.22 & 22,1 & 1896.70 & 327.52 & 74.0 & 12.8 \\
\hline $\mathbf{2 0 0 5}$ & 1957.58 & $-12,0$ & 1825.30 & 132.28 & 80.9 & 5.9 \\
\hline $\mathbf{2 0 0 6}$ & 2307.71 & 17,9 & 2101.22 & 206.50 & 80.9 & 7.9 \\
\hline $\mathbf{2 0 0 7}$ & 2597.22 & 12,5 & 2277.97 & 319.25 & 79.0 & 11.1 \\
\hline $\mathbf{2 0 0 8}$ & 3333.19 & 28,3 & 2943.34 & 390.85 & 81.1 & 10.8 \\
\hline $\mathbf{2 0 0 9}$ & 3818.96 & 14,6 & 3395.17 & 423.80 & 82.4 & 10.3 \\
\hline $\mathbf{2 0 1 0}$ & 3807.33 & $-0,3$ & 3612.39 & 194.94 & 87.8 & 4.7 \\
\hline $\mathbf{2 0 1 1}$ & 5174.02 & 35,9 & 4985.95 & 188.07 & 91.0 & 3.4 \\
\hline $\mathbf{2 0 1 2}$ & 5705.08 & 10,3 & 5491.54 & 213.54 & 91.1 & 3.5 \\
\hline $\mathbf{2 0 1 3}$ & 6470.51 & 13,4 & 6162.75 & 307.77 & 90.6 & 4.5 \\
\hline $\mathbf{2 0 1 4}$ & 6949.14 & 7,4 & 6636.31 & 312.83 & 91.4 & 4.3 \\
\hline $\mathbf{2 0 1 5}$ & 7198.85 & 3,6 & 6853.94 & 344.91 & 91.3 & 4.6 \\
\hline
\end{tabular}

Tablo-3: Dış Borçların Vade Yapısı Kaynak: Fact Fish Verileri (20/02/2017)

Çünkü alındığı borcun verimli bir alana yatırılarak sonradan gelir getirmesi lazım ki daha ülkeye faydalı olsun, gelir getirsin. Bu yüzden borcun ödeme süresi daha uzun olması önemli rol oynar. Ülkemizde uzun vadeli borçlar kısa vadeli borçlara nadiren daha ağırlıklıdır başka bir deyişle uzun vadeli borçlar toplam borcun \%090-\%96'lük kısmına sahip olmaktadır. Fakat uzun vadeli borçların süresi geldiğinde faizleriyle birlikte ödemek gerekir. Bu yüzden uzun vadeli borçların nereye kullanıldığı daha çok önemli olmaktadır. Eğer verimli alanlarda kullanılmazsa ülkenin normal gelirlerinden ödenir ki bütçe açığının yükselme problemi ortaya çıkar ya da borçlar gelecek nesillere kalarak ülkeye dezavantajlı olur. Böylece dış borçlar çok yükselerek kontrol altına alınamaması borçların yönetimi hususunda tehlikeli olacaktır.

\subsection{Kreditörlere Göre Dıș Borçlar}

Kırgızistan'ın en önemli kreditörleri olarak Çin, Rusya, Japonya, Almanya, Türkiye, Kore, Kuveyt, Danimarka, Fransa ve Uluslararası Kalkınma Birliği ile Asya Kalkınma Bankası sayılabilir. Bunların uluslararası kuruluşlardan alınan kredileri genelde indirimli ve hafif koşullara sahiptir. Faiz oranları \%6'dan az olarak sayılır ve belli bir bölümü de silinmiştir. Bazı kreditörlerden alınan borçların vadesi uzatılmıştır. 


\begin{tabular}{|c|c|c|c|c|c|c|c|c|c|c|c|c|}
\hline & 2011 & $\%$ & 2012 & $\%$ & 2013 & $\%$ & 2014 & $\%$ & 2015 & $\%$ & 2016 & $\%$ \\
\hline İMF & 181,80 & 6,48 & 190,53 & 6,28 & 202,73 & 6,41 & 185,20 & 5,38 & 188,20 & 5,22 & 188,04 & 5,0 \\
\hline OPEC & 2,03 & 0,07 & 1,31 & 0,04 & 3,94 & 0,12 & 4,00 & 0,12 & 4,51 & 0,13 & 4,84 & 0,1 \\
\hline $\begin{array}{l}\text { Asya Kalkınma } \\
\text { Bankası }\end{array}$ & 583,36 & 20,8 & 594,65 & 19,6 & 607,07 & 19,2 & 583,57 & 17 & 575,44 & 15,9 & 567,88 & 15,0 \\
\hline $\begin{array}{l}\text { Avrasya Kalkınma } \\
\text { Bankası }\end{array}$ & - & 0 & - & 0 & - & 0 & 0,38 & 0,01 & 3,53 & 0,09 & 5,48 & 0,1 \\
\hline Avrupa Birliği & - & 0 & - & 0 & - & 0 & - & 0 & 5,44 & 0,15 & 15,81 & 0,4 \\
\hline $\begin{array}{l}\text { Uluslararası } \\
\text { Kalkınma Birliği }\end{array}$ & 660,49 & 23,6 & 674,84 & 22,3 & 697,09 & 22,0 & 671,50 & 19,5 & 639,29 & 17,7 & 618,21 & 16,3 \\
\hline $\begin{array}{l}\text { İslam Kalkınma } \\
\text { Bankası }\end{array}$ & 61,05 & 2,17 & 61,72 & 2,03 & 63,95 & 2,02 & 59,02 & 1,72 & 59,48 & 1,65 & 64,59 & 1,7 \\
\hline $\begin{array}{l}\text { Uluslararası Tarımsal } \\
\text { Kalkınma Fonu }\end{array}$ & 9,23 & 0,33 & 8,87 & 0,29 & 8,96 & 0,28 & 9,36 & 0,27 & 9,94 & 0,27 & 12,17 & 0,3 \\
\hline $\begin{array}{l}\text { Kuzey Kalkınma } \\
\text { Fonu }\end{array}$ & 5,95 & 0,21 & 5,93 & 0,19 & 6,06 & 0,19 & 5,21 & 0,15 & 4,57 & 0,12 & 4,31 & 0,1 \\
\hline $\begin{array}{l}\text { Avrupa İmar ve } \\
\text { Kalkınma Bankası }\end{array}$ & 15,41 & 0,55 & 29,63 & 0,97 & 39,99 & 1,27 & 40,61 & 1,18 & 40,95 & 1,14 & 42,45 & 1,1 \\
\hline Çin & 272,62 & 9,72 & 527,47 & 17,4 & 758,43 & 24,0 & 1115,89 & 32,5 & 1296,40 & 36 & 1522,83 & 40,3 \\
\hline Fransa & 5,77 & 0,2 & 5,88 & 0,19 & 6,14 & 0,19 & 5,41 & 0,16 & 4,85 & 0,13 & 4,69 & 0,1 \\
\hline Japonya & 357,38 & 12,8 & 320,56 & 10,6 & 263,21 & 8,33 & 229,39 & 6,67 & 229,02 & 6,35 & 235,99 & 6,2 \\
\hline Almanya & 75,77 & 2,7 & 81,3 & 2,68 & 98,35 & 3,11 & 102,4 & 2,98 & 100,07 & 2,78 & 81,72 & 2,2 \\
\hline Kore & 14,82 & 0,53 & 15,94 & 0,52 & 17,37 & 0,55 & 16,66 & 0,48 & 15,61 & 0,43 & 15,12 & 0,4 \\
\hline Kuveyt & 13,31 & 0,47 & 10,66 & 0,35 & 9,26 & 0,29 & 8,64 & 0,25 & 9,73 & 0,27 & 8,55 & 0,2 \\
\hline Rusya & 300,00 & 10,7 & 300,00 & 9,89 & 300,00 & 9,49 & 300,0 & 8,73 & 300,00 & 8,33 & 270,00 & 7,1 \\
\hline Suudi Fonu & - & 0 & 0,18 & 0,01 & 1,27 & 0,04 & 3,87 & 0,11 & 7,43 & 0,20 & 11,17 & 0,30 \\
\hline Türkiye & - & 0 & 10,00 & 0,33 & 70,54 & 2,23 & 90,00 & 2,62 & 97,00 & 2,69 & 97,00 & 2,6 \\
\hline Abu-Dabi & & & & & 1,06 & 0,03 & 2,64 & 0,08 & 6,42 & 0,18 & 8,76 & 0,23 \\
\hline Danimarka & 3,35 & 0,12 & 3,34 & 0,11 & 3,31 & 0,1 & 3,27 & 0,09 & 3,20 & 0,08 & 3,13 & 0,1 \\
\hline
\end{tabular}

Tablo-4: Kreditörlere Göre Dış Borçlar (milyon dolar) Kaynak: Kırgızistan Cumhuriyeti Maliye Bakanlığı (20/02/2017)

Dış borçların \% 40’ı Çin (Çin Cumhuriyeti İhracat-İthalat Bankası), \% 16’sı Uluslararası Kalkınma Birliği ve \% 15'i Asya Kalkınma Bankasına aittir. Dış borçların 2250 milyon ABD doları iki taraflı imtiyazlı borçlar, 1481 milyon ABD doları çok taraflı imtiyazlı borçlardır. İki taraflı imtiyazsız borç kreditörlerinin ilk sırasında 5,73 milyon dolar veren Germes Kreditverziherungs-Aktingezeliaft (Almanya) olmaktadır ve toplam iki taraflı imtiyazsız dış borç stoğu 8,86 milyon dolardır. Çok taraflı imtiyazsız borcu ise sadece Avrupa İmar ve Kalkınma Bankası (42,45 milyon dolar) vermiştir.

Çok taraflı borçların nominal değeri 2016 yılı Aralık ayı itibariyle 1523,78 milyon dolardır. Bunun 1481,33 milyon doları imtiyazlı iken 42,45 milyon doları imtiyazsız borçlardır (Kırgız Cumhuriyeti Maliye Bakanlığı, www.minfin.kg, 31.12.2016. Başka bir değişle toplam dış borcun \% 98,6 imtiyazlı iken \%1,4'ü imtiyazsız dış borç olmaktadır. Geri ödeme süresi de 15-40 senedir ve bunun 5-10 senesi ise imtiyazlı iken faizleri genel olarak \%0,752,5 olmaktadır. İki taraflı borçların da çoğunluğu imtiyazlıdır. Geri ödeme süresi 10-30 sene, bunun imtiyazlı süresi 5-10 senedir. Faiz oranları ise \%0,1-5 olmaktadır (Soy, 02/11/2016)

Geçiş döneminde kaynak yetersizliğinden dolayı önemli altyapı hizmet ve malların üretimi (yol yapmak, elektrik üretimi v.d. hizmetler) dış borçlar aracılığı ile gerçekleştirilmiştir (IMF, 2016: 8). Dış borçlar ülkenin tarım sektörüne, sosyal yardımlara, altyapı ve iletişimi geliştirmek ve başka alanlar için harcanmıştır (Koyçumanov ve Osmonaliyev, 2003). Daha ayrıntılı olarak \%24'ü enerji alanına, \%24-28'i yol altyapısına, \%20'si tarım sektörüne ve kalan kısmı ise bütçe açı̆̆ın kapatmak için harcanmıştır (Kocobayeva, 05/03/2017).

Dış borçların önemli kısmının yol gibi altyapı hizmetleri için harcandığına rağmen Dünya Bankasının verilerine göre Kırgızistan 2013-2014 yıllarında altyapı hizmetlerinin kalitesine göre 148 ülke arasından 108. sıradadır. Ayrıca yolların kalitesine göre 133. sırada, elektrik enerjisi ile ilgili 122. sırada olduğu açıklanmıştır (World Bank, 2014: 30).

Dış borçlar alınırken uygulanacak projelerin seçim prosedürü, yapılan fayda maliyet analizleri hakkında hükümet halka bilgi vermemektedir. Bununla birlikte dış borçların kullanım alanları ve alınan faydaları hakkında da bilgi bulmak zordur. Bununla birlikte dış borçların risklerinin de hesaplanıp hesaplanmadığı kesin belli değildir. Dış borçların saydamlığının düşük olması halkın devlete olan güvenini azaltabilecektir. Dolayısıyla dış borçlar ve genel olarak borçları seçiminde, kullanılacak alan veya projelere karar vermede ve riskleri hesaplayıp en düşük maliyetle en yüksek faydaları sağlayacak borçları ve projeleri belirleyecek ve borçlar hakkında geniş ve detaylı rapor hazırlayan borç ofisinin kurulması gerekmektedir.

İç borçlar ise ülkedeki zaten az olan tasarrufları azaltarak sermaye kıtlığını daha da yükselttiği tahmin edilebilir. Çünkü ticari bankalar iç borç enstrumanlarının faizleri yükselirken mevduatlarını kredilere değil bu menkul kıymetlere yönlendirebilmektedirler. İç borçların faizleri de dış borçlara kıyasla daha yüksektir. Dolayısı ile iç borçların minimize edilmesi ekonomi için daha iyi etkide bulunabilir.

Borçların sürdürülebilirliğinin arttırılması için uzun vadeli dış borçları daha etkin ve gelir getirebilen alanlara, daha ayrıntılı söylersek, ülkenin üretim kapasitesini arttıran ve işsizliği azaltabilen büyük fabrikaların kurulmasına kullanılması daha uygun olabilir. 
Borç servisini kolaylaştırmanın yolu döviz gelirleri artışından geçmektedir. Bu amaçla ülkenin uluslararası ticaretteki payını arttırıcı ve alınan kredilerin üretken yatırımlarda kullanılmasını sağlayıcı politikalar uygulaması gerekir. turizmi geliştirici önlemler alınmalıdır. dar olan vergi tabanının genişletilmesi, kayıt dışı ekonominin kayıt altına alınması, yatırımları ve üretimi teşvik edici bir vergi politikasının uygulanması gerekmektedir (Canbay, 2005).

\subsection{Borç Rasyolarıyla Kırgızistan}

Dünya Bankası ülkenin çok borçlu olup olmadığını dört kritere göre belirlemektedir. Bunlar TDB/GSYİH, TDB/İhracat, TDB Servisi/İhracat ve TDB Faiz Servisi/İhracat oranlarıdır. Bu kriterlerden her biri ayrı ayrı olarak değerlendirilir ve üçü çok borçlu rasyosuna ulaşmışsa o ülke çok borçlu ülke olarak sayılır (Sarı, 2004). Bu rasyolar açısından Kırgızistan'ı değerlendirdiğimizde aşağıdaki sonuçlara ulaşabiliriz.

\begin{tabular}{|l|r|r|r|r|r|r|r|r|}
\hline & $\mathbf{2 0 1 1}$ & $\mathbf{2 0 1 2}$ & $\mathbf{2 0 1 3}$ & $\mathbf{2 0 1 4}$ & $\mathbf{2 0 1 5}$ & $\mathbf{2 0 1 6}$ & \multicolumn{1}{c|}{$\begin{array}{c}\text { Orta } \\
\text { Derecede } \\
\text { Borçluluk } \\
\text { Aralığı }\end{array}$} & $\begin{array}{c}\text { Cok } \\
\text { Borçluluk } \\
\text { Sımır Oranı }\end{array}$ \\
\hline $\begin{array}{l}\text { Toplam D1ş } \\
\text { Borç (TDB) } \\
\text { milyon dolar }\end{array}$ & 5174.02 & 5705.08 & 6470.51 & 6949.14 & 7198.85 & 3782,74 & & - \\
\hline TDB/GSYİH & 47,7 & 47,2 & 44,4 & 54,1 & 64,5 & 56,6 & $30-50$ & 50 'nin üzeri \\
\hline TDB/İhracat & 230.76 & 295.96 & 322.42 & 368.9 & 489.65 & 244.9 & $165-275$ & 275 'in üzeri \\
\hline $\begin{array}{l}\text { TDB } \\
\text { Servisi/İhracat }\end{array}$ & 37.2 & 37.8 & 38.7 & 50.6 & 67.0 & 85.8 & $18-30$ & 30 'un üzeri \\
\hline $\begin{array}{l}\text { TDB Faiz } \\
\text { Servisi/İhracat }\end{array}$ & 18.1 & 16.7 & 16.9 & 21.9 & 25.3 & 31.3 & $12-20$ & 20 'nın üzeri \\
\hline
\end{tabular}

Tablo-5: Dış Borç Göstergeleri Kaynak: Kırgızistan Cumhuriyeti Maliye Bakanlığı, Kırgızistan Cumhuriyeti Istatistik Komitesi (10/04/2017)

Tabloda da görüldüğü gibi Kırgızistan TDB’un GSYİH’ya oranı açısından belirlenmiş olan \%50'lik sınırı 2014 yılında aşmıştır. TDB'un ihracata olan oranı 2016 yılında iki katına azalmışken TDB servisinin ihracata oranının sürekli arttığını görmekteyiz. Bu ise ülkenin borç sevisinde ciddi sorunlar olabileceği tehlikesinin sinyali olabilir. Dolayısı ile ülkede üretim kapasitesinin arttırılması gerekmektedir.

\section{Sonuç}

Kırgızistan bağımsızlığını kazandıktan sonra piyasa ekonomisine geçiş sürecinde ciddi krizleri yaşamıştır. İlk dönüşüm dönemi en ağır yıllardan olmuştur. 1996 yılından itibaren gelişmeye başlamıştır. Ülke reformları gerçekleştirmek ve ekonomik büyümeyi hızlandırmak amacıyla borçlanmak zorunda kalmıştır.

Ülkede sermaye yetersizliğinden dolayı alınan borçların \% 90’u dış borçlardır. Toplam dış borçların GSYİH'ya oranı 2016 yılında \% 56.6 iken iç borçlar \% 0.07'dir. Borç rasyolarına göre son yıllarda çok borçlu ülkeye girmişizdir. Bu durum borç yönetiminin etkinleştirilmesi gerektiğini ortaya koymaktadır.

Borç yönetiminin geliştirilmesi için borçların seçimi, risklerinin analizi ve borçlarla finanse edilecek projelerin titiz analizini yapacak ve sonuçta borçlarla ilgili detaylı rapor hazırlayacak borç ofisinin kurulması gerekmektedir.

Dış borçların kullanım alanları ve elde edilen faydalar hakkında halkı bilgilendirerek borçların saydamlığı sağlanmalıdır. Dış borçların yol yapmak gibi altyapı hizmetlerine harcanmasından daha çok ülkenin üretim ve ihracat kapasitesini arttıracak alanlara kullanılması gelecekte borç servisi açısından faydalı olabilir.

\section{Kaynakça}

- Adıyaman, A.T. 2006. "Dış Borçlarımız ve Ekonomik Etkileri” Sayıştay Dergisi, Sayı:62, s.21-45

- $\quad$ Ateş, G. 2002. "Borç Yönetimi Ofisi ve Türkiye Uygulaması Üzerine Bir Çalışma", T.C Başbakanlık Hazine Müsteşarlı̆̆, S.1-4

- Canbay, T. 2005. “Kırgızistan'da Dış Borç ve Borç Yönetimi Sorunu”, Uluslararası Hakemli Sosyal Bilimler E-Dergisi, Say1: 6, s.1-11

- Çaşkurlu, E. 2003, “1980 Sonrası Dönemde Merkez Bankasından Kaynak Kullanımının Makro Ekonomik Etkilerinin Analizi”, Gazi Üniversitesi İktisadi ve İdari Bilimler Fakültesi Dergisi, Cilt:5, Sayı:1, s.189-208

- Çataloluk, C. 2009. "Kamu Borçlanması, Gerçekleşme Biçimi ve Makro Ekonomik Etkileri (Teorik Bir Yaklaşım, Türkiye Örneği)” Balıkesir Üniversitesi, SBE Dergisi, Cilt:12, Sayı:21, s.240-258

- DEİK (Dış Ekonomiler İlişkiler Kurulu) 2012 Kırgızistan ülke bülteni,

- $\quad$ Eker, A ve Meriç, M. 2000. Devlet Borçları. Anadolu Matbaası. İzmir.

- $\quad$ Fact Fish verileri: 
- http://ftp.factfish.com/statistic-country/kyrgyzstan/external\%20debt $\% 20$ stocks $\% 2 \mathrm{C} \% 20$ short-term 20/02/2017

- http://ftp.factfish.com/statistic-country/kyrgyzstan/external $\% 20 \mathrm{debt} \% 20$ stocks $\% 2 \mathrm{C} \% 20$ long-term 20/02/2017

- $\quad \mathrm{http}: / / \mathrm{stat} . \mathrm{kg} / \mathrm{kg} / \mathrm{statistics/finansy/,(05.10.2016)}$

- http://www.minfin.kg/novosti/novosti/na-31-dekabrya-2016-goda-razmer-gosdolga-kr-sostav.html (31/03/2017),

- $\quad$ http://www.minfin.kg/ru/novosti/mamlekettik-karyz/gosudarstvennyy-dolg/struktura-gosdolga-posostoyaniyu-na-31-dekabrya-2.html (10/04/2017),

- http://www.minfin.kg/ru/novosti/mamlekettik-karyz/gosudarstvennyy-dolg/struktura-gosudarstvennogodolga-za-yanvar-dekabr-.html_(10/04/2017),

- http://www.minfin.kg/ru/novosti/mamlekettik-karyz/obsluzhivanie-gosudarstvennogo-dolga/za-dvamesyatsa-2017-goda-na-obsluzhivanie-gosdolg.html_(10/04/2017)

- http://www.stat.kg/kg/statistics/download/dynamic/516/_(10/04/2017)

- IMF, 2016. IMF Staff Country Report No. 16/186, International Monetary Fund, Publication Services, 700 19th Street, N.W. Washington, D.C. 20431.

- Kirgiz Cumhuriyeti İstatistik Komitesi verileri

- Kırgız Cumhuriyeti Maliye Bakanlığı verileri

- Kırgız Cumhuriyeti Merkez Bankası verileri, http://www.nbkr.kg/index1.jsp?item=137\&lang=KGZ (02.03.17)

- $\quad$ Kocobayeva, Z. 2016. Azattık Radyosu Kaynakları, http://www.azattyk.org/a/kyrgyzstan_economy_debt/28157315.html 05/03/2017

- Obşestvo Obediyennıh Natsiy(OON) Yıllık Yayınları: Kırgızskaya Respublika: Obşaya Otsenka Stranı Sistema OON v Kırgızskoy Respublike, Bişkek, 2003

- Orhaner, E. 1997. Kamu Maliyesi. Gazi Kitabevi. Ankara.

• Özdemir, P. 2009. "İç Borç Yönetimi ve Türkiye”, T.C. Çukurova Üniversitesi, SBE, İktisat Anabilim Dalı, Yüksek Lisans Tezi, Adana

- Sarı, M. 2004. "Dış Borç Yönetimi ve Türkiye Uygulamaları”, Türkiye Cumhuriyeti Merkez Bankası Dış İlişkiler Genel Müdürlüğü, Uzmanlık Yeterlilik Tezi, Ankara

- $\quad$ Soy, M. 2013. Veçerniy Bişkek Gazetesi Kaynakları http://www.vb.kg/doc/226539_vneshniy_dolg_kyrgyzstana_sostavliaet_pochti_poloviny_vvp.html_ $02 / 11 / 2016$

- Syzdykova, A. ve Abubakirova, A. 2016. "Kazakistan'da Dış Borç ve Borç Yönetimi Sorunu” Вестник Карагандинского университета, EOS 336.14(574), s.68-74

- Tandırcıoğlu, H. 2000, “Türkiye'de Dış Borç Sorunu, Dış Borçların Sürdürebilirliği ve Dış Borçların Sınırlandırılması”, Dokuz Eylül Üniversitesi SBE dergisi, Cilt:2, Sayı:2, s.260-284

- World Bank. 2014. Kyrgyz Republic - Public expenditure review policy notes : strategic setting. Public Expenditure Review (PER). Washington, D.C. : World Bank Group. http://documents.worldbank.org/curated/en/2015/06/24607685/kyrgyz-republic-public-expenditure-reviewpolicy-notes-strategic-setting 